\title{
New Bacterial Surface Display System Development and Application Based on Bacillus subtilis YuaB Biofilm Component as an Anchoring Motif
}

\author{
Daeun Kim, Wooil Kim, and Junehyung Kim
}

Received: 29 December 2020 / Revised: 7 January 2021 / Accepted: 7 January 2021

(C) The Korean Society for Biotechnology and Bioengineering and Springer 2021

\begin{abstract}
Bacterial surface display system has been adopted in various biotechnological applications. In the case of Bacillus subtilis, most of the studies have been developed using spore based surface display system utilizing the inherent rigidity of spore against heat, alkali, and shear stress. But, spore harvest, purification and separation need additional cost and labor. To eliminate this procedure and to use the gram-positive nature of B. subtilis, YuaB, which is one of the major $B$. subtilis biofilm components and locates in the cell wall, based cell surface display system, is developed. P43 promoter driven overexpression of YuaB-His $_{6}$ tag does not hamper bacterial cell growth and promoted biofilm formation of recombinant strain. Flow cytometry of recombinant strain and its protoplast using FITC-Anti $\mathrm{His}_{6}$ antibody, verified that YuaB locate in plasma membrane and protrude to the outside of cell wall, which means YuaB can be used as very efficient anchoring motif. Using surface expressed YuaB-His ${ }_{6}$ tag, removal of divalent metal ion, $\mathrm{Cu}^{2+}$ and $\mathrm{Ni}^{2+}$, was tried to test its possibility for the environmental application of developed system.
\end{abstract}

Keywords: YuaB, flow cytometry, Bacillus subtilis, bacterial surface display system, protoplast

Daeun Kim, Wooil Kim, Junehyung Kim*

Department of Chemical Engineer, Dong-A University, Busan 49315, Korea

Tel: +82-200-7719; Fax: +82-51-200-7728

E-mail: june0302@dau.ac.kr

Junehyung Kim

Center for Sliver-Targeted Biomaterials, Brain Busan 21 Plus Program, Graduate School, Dong-A University, Busan 49315, Korea

\section{Introduction}

With increasing interest of global warming and environment, bioengineering has emerged as a promising alternative of chemical engineering industry. Application of bioengineering techniques can prevent formation of harmful byproducts, which is a main problem of chemical production process $[1,2]$. In bioengineering, many kinds of microorganisms have been widely used and studied in various field such as chemical [3,4], biopolymer [5,6], pharmaceutical $[7,8]$, and nutraceutical [9]. Some of most popular microorganisms in biomanufacturing are Escherichia Coli, Corynebacterium species, Bacillus species, Pseudomonas species, Clostridium Species, and Saccharomyces cerevisiae [10].

Among numerous species, Bacillus subtilis has been considered as attractive bacterium for industrial application. $B$. subtilis is a gram-positive bacterium which has distinct features such as good growth on cheap carbon source, clear inherited backgrounds, having genetic manipulation method, robustness in large-scale fermentation, spore formation and biofilm formation [11]. In addition, B. subtilis has been designated as generally recognized as safe (GRAS) according to the World Health Organization (WHO) [12]. A number of bio-products were already produced with dynamic strategies of engineering B. subtilis including metabolic optimization and spore display.

Bacterial surface display system has been applied in various biotechnological and industrial fields such as vaccine, biocatalyst, and biosensor development [13]. Bacterial surface display system was first introduced in 1986 by Roland Freudl et al. [14]. OmpA, which is one of the major outer membrane proteins of $E$. coli $\mathrm{K}-12$ and exposed to external environment, was used as an anchoring motif for surface display system [14]. Recently, displaying laccase, CotA, of $B$. subtilis which has enzymatic activity decomposing 
synthetic dye, on E. coli surface has been reported [15]. In the case of $B$. subtilis, most of studies have been focused on development of spore surface display system. B. subtilis spore is composed of peptidoglycan layer called the cortex, multilayer protein coat, and an outer coat layer [16]. Under harsh conditions such as heat, $\mathrm{pH}$, ultraviolet radiation, and chemical stress, $B$. subtilis enters into the resting phase of sporulation and survive for a long time [12]. Due to its attributes, spore display system has been recognized as most promising engineering technology.

However, spore surface display system has some defects. In order to use spore of $B$. subtilis, bacterial cells have to be cultivated at least $24 \mathrm{~h}$, because $B$. subtilis forms spores when they are exposed to environmental stress, like lack of nutrients. Moreover, after $24 \mathrm{~h}$ cultivation, we need additional process to isolate spore from cell. Commonly, spores have been separated by density difference between spore and cell with some chemicals that can provide density gradient such as PEG (poly ethylene glycol) [17] and Renografin (sodium diatrizoate hydrate) [18]. Spore separation process is complicate and highly expensive process, also difficult to get pure and large amounts of spores. Although spore display system has some drawbacks, cell surface display system of $B$. subtilis has not been studied as much as spore display system developed. Few studies have been reported by using sortase and sortase substrate $[19,20]$. Sortase makes covalent bond between $B$. subtilis cell wall and sortase substrate, but specific mechanism of $B$. subtilis sortase system is not certainly revealed yet.

B. subtilis forms rugose pellicles called biofilm, which is the group of bacterial societies by sticking cells each other [21]. Biofilm of B. subtilis is composed of self-produced extracellular matrix including exopolysaccharide (EPS), proteins, and some nucleic acid [22,23]. Development of biofilm is strictly regulated by gene expression of extracellular matrix components. Under certain conditions, for instance, nutrient depletion, impaired respiration or surface adherence [24-26], B. subtilis switches from a planktonic to a sessile state and start to stimulate genetic expression regarding production of extracellular components. After expansion and maturation of biofilm, it continues development by secretion of self-produced extracellular matrix. As a result, extensive wrinkles are created at the surface of biofilm matrix. Ruggedness of biofilm provides several advantages for the bacterial society. By increasing surface-to-volume ratio, bacteria within the biofilm have a greater access to oxygen [24,27]. In addition, biofilm has well-defined channels, which can transport liquid through extracellular matrix [28]. Liquid flux is crucial for providing nutrients and disposal of wastes. Moreover, genetic differentiation and sporulation of $B$. subtilis depend on the location inside the biofilm matrix [29]. It means that biofilm brings heterogeneity of cellular phase of $B$. subtilis.

EPS and proteins comprise of structural biofilm [30]. EPS, one of the major molecules of biofilm, is controlled by the espA-O gene operon (eps) [29-31]. However, the specific structure of EPS has not been fully understood. A study regarding the role of eps has been reported as deficiency of resulted in formation of weak and fragile pellicles. Although, other matrix components support deficiency of EPS and EPS mutant can keep growing in extracellular matrix [30]. TasA and TapA are two important proteins, which are the products of three-gene operon tapAsipW-tas $A$ (tapA operon) [32]. Long intercellular amyloid fibers, which provide structural stability of biofilm, are formed by self-assembly of TasA protein [30,33]. This amyloid fibers anchor to the cell wall with the help of TapA [33]. Additionally, YuaB (or BslA) is essential protein for the maturation of $B$. subtilis biofilm. Deletion of $y u a B$ presents reduced complexity of the biofilm architecture and cannot be compensated by overexpression of other extracellular components. Importantly, YuaB interact with the Tas A amyloid fiber and the EPS polymer as synergistic manner to maturate biofilm. However, YuaB does not affect production of EPS and TasA [34]. In the early secretome study of B. subtilis, YuaB has been presumed as an extracellular protein [35]. However, recently, it has been discovered that YuaB is an cell-associated protein, which locates in the cell wall [34]. YuaB has putative signal peptide sequence, 28 amino-acid at its $\mathrm{N}$-terminus, and transmembrane region. The signal sequence removed YuaB neither have wild type function nor be detected in the cytoplasm [34]. Signal peptide of YuaB is vital for secretion and function of YuaB.

In this study, YuaB was used as an anchoring motif for development of a new $B$. subtilis cell surface display system. This is the first attempt to display target protein on the B. subtilis cell surface by using a biofilm component, YuaB. We fused $\mathrm{His}_{6}$ tag at the C-terminus of YuaB to analyze the possibility as anchoring motif in surface display. p43 promoter, which is overlapping promoters transcribed by B. subtilis $\sigma^{55}$ and $\sigma^{37}[36]$, is also fused at $\mathrm{N}$-terminus of YuaB to stimulate production of YuaB fusion protein. We confirmed that YuaB can be used for B. subtilis cell surface display system by analyzing recombinant cells with flow cytometry. Furthermore, a new surface display system has been applied heavy metal adsorption and showed positive potential of its industrial utilization.

\section{Materials and Methods}

\subsection{Bacteria and growth condition}

Two protease deficient B. subtilis DB104 (trpC2 nprE 
$a p r E$ ) was used as a host strain [37], for the expression host of YuaB-His ${ }_{6}$ tag. All B. subtilis cells were grown in Schaeffer's medium containing Difco Nutrient broth, $0.25 \mathrm{~g}$ $\mathrm{MgSO}_{4} \cdot 7 \mathrm{H}_{2} \mathrm{O}$ and $1 \mathrm{~g} \mathrm{KCl}$ per liter. After autoclaving, $1 \mathrm{~mL}$ of each filtered stock solution $\left(\mathrm{FeSO}_{4} \cdot 7 \mathrm{H}_{2} \mathrm{O} 10^{-3} \mathrm{M}\right.$, $\mathrm{MnCl}_{2} \cdot 4 \mathrm{H}_{2} \mathrm{O} 10^{-2} \mathrm{M}$, and $\mathrm{CaCl}_{2} \cdot 2 \mathrm{H}_{2} \mathrm{O} 1 \mathrm{M}$ ) was added and supplemented with Chloramphenicol $(20 \mu \mathrm{m} / \mathrm{mL})$ [38]. $E$. coli strain DH5 $\alpha$ was used for $E$. coli transformation. All $E$. coli cells were grown under the condition at $37^{\circ} \mathrm{C}$, $180 \mathrm{rpm}$ in LB media. Chloramphenicol $(20 \mu \mathrm{m} / \mathrm{mL})$ was used as a selective marker.

\subsection{Construction vector and strain}

pSDJH100 [38] was used for pDE100-Y1 vector construction. Chromosome of DB104 was used for PCR template. p43 promoter was amplified with primers $\mathrm{p} 43-5$ ' (5'-tca aaaggatcetgcatg cag gccggggca tat-3') and p43-3' (5'-ttg tctctgcaggtgtacattcctctcttacct- $3^{\prime}$ ) by PCR. pSDJH 100 and p43 PCR fragment were digested with restriction enzyme Bam I and Pst I, which is included in vector and PCR fragment, and ligated with T4 ligase. pSDJH100 containing p43 promoter was named as pDE100. yuaB was amplified with primers YuaB-5' (5'-ctgcagatgaaacgcaaattattatct-3') and YuaB-3'(5'-ctcgagttaatgatgatgatgatgatggtcgacgttgcaacc gcaaggctgagt-3') by PCR using DB104 chromosome as a template. $\mathrm{His}_{6}$ tag was integrated in the YuaB-3' primer, which is indicated by shading. Vector pDE100 and PCR fragment of YuaB were digested with restriction enzyme Pst I and Xho I, then ligated with T4 ligase to construct expression vector $\mathrm{pDE} 100-\mathrm{Y} 1$.

\subsection{Protoplast isolation}

B. subtilis grew in $50 \mathrm{~mL}$ for $10 \mathrm{~h}$ and was harvested by centrifuge (10 min, $6000 \mathrm{rpm}$ ). Supernatant was discarded and cell pellet was washed twice with SET buffer, which contains sucrose $(20 \%$ [wt/vol] $)$, Tris- $\mathrm{HCl}(50 \mathrm{mM}, \mathrm{pH}$ 7.6), and EDTA (50 mM). After washing, pellet was suspended with $1 \mathrm{~mL}$ of isotonic buffer solution (TMS) containing Tris- $\mathrm{HCl}(50 \mathrm{mM}, \mathrm{pH} 8.0), \mathrm{MgCl} 2$ (16 mM), and sucrose $(33 \%$ [wt/vol]). Cell suspension was divided into $300 \mu \mathrm{L}$ aliquots. To remove peptidoglycan layer, lysozyme (1 mg/mL final concentration) and phenylmethane sulfonyl fluoride $(0.1 \mathrm{mM}$, final concentration) were added. Suspension was incubated at $37^{\circ} \mathrm{C}$ for $1 \mathrm{~h}$. Protoplasts were pelleted (15 min, $13000 \mathrm{rpm}$ ) and supernatant was carefully discarded [39].

\subsection{Flow cytometry analysis}

DB104 and DB104(pDE100-Y1) were grown in $50 \mathrm{~mL}$ of Schaeffers' media for $10 \mathrm{~h}$. Cells were harvested by centrifuge (10 min 6,000 rpm) and washed with phosphate buffered saline (PBS) twice. Protoplasts were washed twice with
SET buffer. Bacterial cells and protoplasts were suspended in $100 \mathrm{~mL}$ of each PBS and SET buffer, which contains an antibody (1:220) (Rabbit Poly Anti-6-His, FITC, K0212220, Komabiotech, Korea) and reacted $1 \mathrm{~h}$ in the ice. After reaction, vegetative cells and protoplasts were washed 3 times with PBS and SET buffer. Analysis was taken place by Flow cytometry (Beckman Coulter Epics XL).

\subsection{Heavy metal adsorption analysis}

DB104 and DB104(pDE100-Y1) were grown in $100 \mathrm{~mL}$ of Schaeffers' media for $10 \mathrm{~h}$. Cells were harvested by centrifuge (10 min, 6,000 rpm) and washed twice with distilled water. Each cell was suspended in $1 \mathrm{~mL}$ of sterile water. Suspended cell was measured by UV spectrometer to set the same sample O.D. Each reaction samples were fitted to O.D. $3000(600 \mathrm{~nm})$.

Copper(II) chloride solution (0.0001\%) and nickel sulfate solution $(0.000025 \mathrm{M})$ were used for heavy metal adsorption by bacterial cell. Each metal ion samples were prepared as standard, negative control and analyte. Final cell suspensions were inoculated in $10 \mathrm{~mL}$ of $0.0001 \%$ copper(II) chloride and $0.000025 \mathrm{M}$ Nickel(II) sulfate. The mixtures of heavy metal and cell suspension were cultivated at $37^{\circ} \mathrm{C}, 180 \mathrm{rpm}$, $1 \mathrm{~h}$ for adsorption. After $1 \mathrm{~h}$ reaction, the mixtures were centrifuged for 10 min with $6,000 \mathrm{rpm}$ to remove cell and supernatant were analyzed with atomic adsorption spectroscopy (Perkin Elmer, AAnalyst800).

\section{Results}

\subsection{Construction of $\mathrm{YuaB}^{-\mathrm{His}_{6}}$ tag expression vector and $B$. subtilis strain}

In this study, a pSDJH100 vector based on pCSK1 was used, which is an E. coli/B. subtilis shuttle vector, for the expression of $\mathrm{His}_{6}$ tag at the C-terminal end of YuaB anchoring motif. For the maximal vegetative surface expression of YuaB-His ${ }_{6}$ tag on B. subtilis vegetative cell, we used strong p43 promoter, which is overlapping promoters transcribed by $B$. subtilis $\sigma^{55}$ and $\sigma^{37}(36)$, which originally transcribe cytidine/deoxycytidine deaminase in B. subtilis. pSDJH100 containing $\mathrm{p} 43$ promoter was named as pDE100.

For the promising new anchoring motif, YuaB, which is a cell-associated protein, which located in the cell wall [34], was selected. YuaB has putative signal peptide sequence, 28 amino-acid at its $\mathrm{N}$-terminus, and transmembrane region, which strongly suggest it can be a good surface anchoring motif for the display of target protein.

For the efficient verification of surface expression of YuaB, it was designed that YuaB-3' (5'-ctcgagttaatgatgatg atgatgatggtcgacgttgcaaccgcaaggctgagt-3') primer contains 


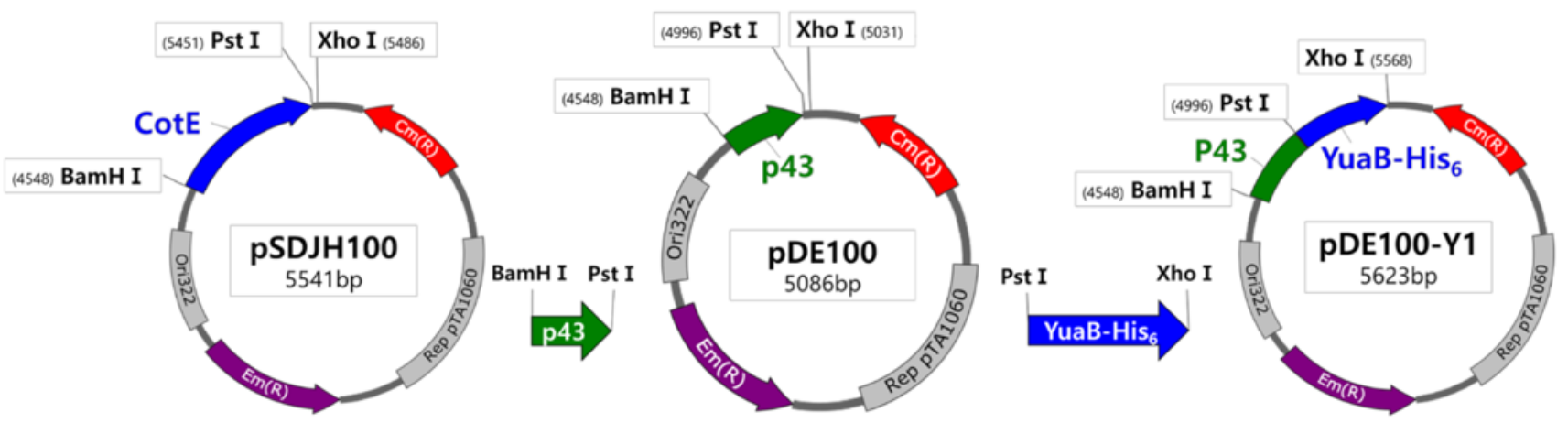

Fig. 1. Construction of pDE100 expression vector. The amplified fragment containing p43 promoter and pSDJH100 vector were digested with Bam HI and Pst I and ligated to yield pDE100. Constructed pDE100 and PCR fragment containing YuaB-His tag $_{6}$ were digested with Pst I and Xho I and ligated to yield pDE100-Y1.

$\mathrm{His}_{6}$ tag at the C-terminal end of anchoring motif.

Vector pDE100 and PCR fragment of yuaB- $\mathrm{His}_{6}$ tag were digested with restriction enzyme, Pst I and Xho I, and ligated with $\mathrm{T} 4$ ligase to construct expression vector pDE100-Y1.

The constructed expression vector was extracted using plasmid mini prep kit (plasmid SV mini, Geneall, Korea) and the correct insertion of gene into the plasmids was verified by sequencing analysis. The construction of pDE100-Y1 is shown in Fig. 1. The recombinant plasmid was transformed into strain DB104 followed by selection on LB plates containing chloramphenicol. Constructed strain was named as DB104(pDE100-Y1).

\subsection{Bacterial cell growth and biofilm formation of constructed strain}

The N-terminus of YuaB is located at cytoplasmic membrane of B. subtilis. Then it penetrates through the cell wall and, the C-terminus of YuaB is located at the extracellular region. As YuaB is a composition of cell wall, the growth

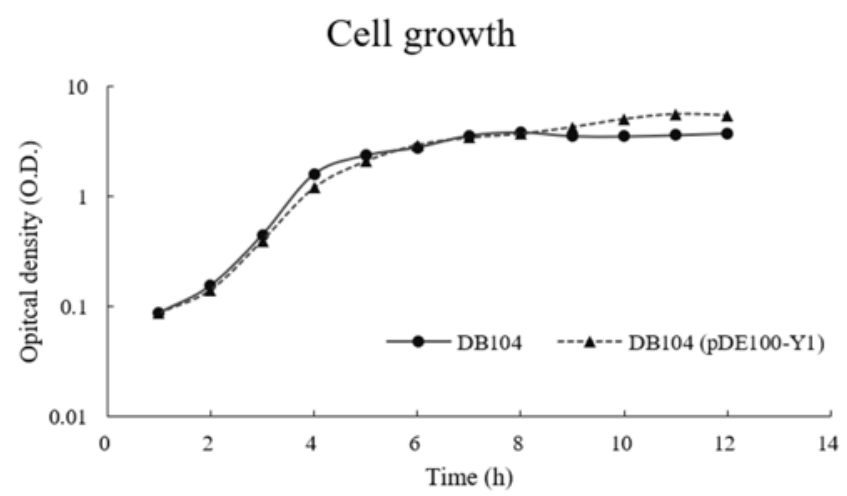

Fig. 2. Bacterial cell growth of DB104 (O) and DB104(pDE100Y1) ( $\Delta$ ). Both strains were grown under the condition at $37^{\circ} \mathrm{C}$, $180 \mathrm{rpm}$ in LB media. Chloramphenicol $(20 \mu \mathrm{m} / \mathrm{mL})$ was used as a selective marker for DB104(pDE100-Y1). Optical density of both cultures was measured every hour. curve of $B$. subtilis has been drawn to check whether the overexpressed YuaB-His 6 tag affect cell growth or cell viability. Wild type, DB104 and recombinant cell, DB104 (pDE100-Y1), was inoculated in $50 \mathrm{~mL}$ of Schaeffer's media with the same O.D. Both cells were grown under the condition of $37^{\circ} \mathrm{C}$ at $180 \mathrm{rpm}$. Every $1 \mathrm{~h}$, optical density was measured. Fig. 2 shows that the overexpression of YuaB-His $_{6}$ tag does not affect cell growth and viability in planktonic growth $B$. subtilis.

YuaB plays a major role in biofilm formation. YuaB deleted mutant strain does not form biofilm. In other words, when other proteins, which involve in biofilm formation, such as DegU, TasA, lose their function, YuaB can compensate their absence [34]. pDE100-Y1 vector is designed to overexpress YuaB-His $_{6}$ tag under the control of $\mathrm{p} 43$ promoter. Therefore, capability of biofilm formation of DB104 and DB104(pDE100-Y1) has been compared. Both strains were inoculated into sterile flask with $50 \mathrm{~mL}$ of

A

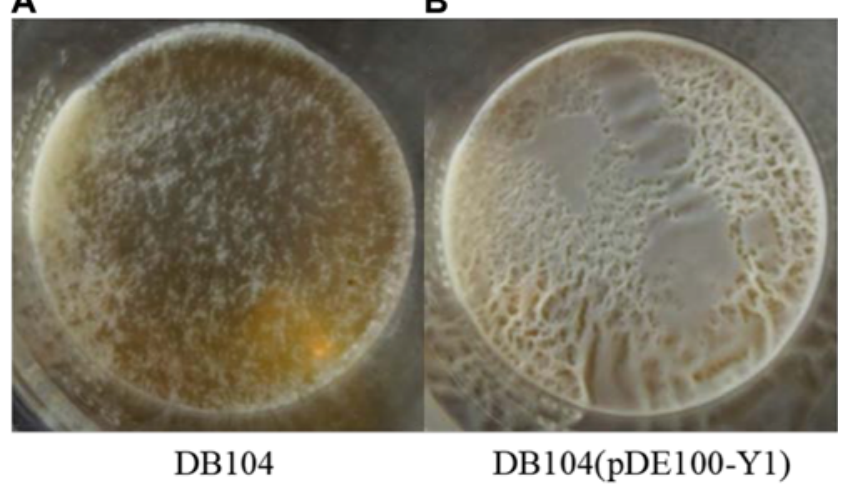

Fig. 3. Biofilm formation between wild type DB104 and DB104(pDE100-Y1), which overexpresses YuaB-His 6 tag. Both strains were inoculated into sterile flask with $50 \mathrm{~mL}$ of Scaeffer's media with initial same O.D. In the case of DB104(pDE100-Y1), chloramphenicol $(20 \mu \mathrm{L} / \mathrm{mL})$ was added in the medium. Both culture were sustained for $72 \mathrm{~h}$ at $30^{\circ} \mathrm{C}$ without shaking. 
Scaeffer's media with initial same O.D. In the case of DB104(pDE100-Y1), chloramphenicol $(20 \mu \mathrm{L} / \mathrm{mL})$ was added in the culture medium. Both culture were sustained for $72 \mathrm{~h}$ at $30^{\circ} \mathrm{C}$ without shaking. Both strains formed biofilm at the liquid-air interface. DB104(pDE100-Y1) builds more thick and wrinkled biofilm than wild type DB104 (Fig. 3). This result indicates that DB104(pDE100-Y1) overexpressed functional $\mathrm{p} 43 \mathrm{YuaB}^{\mathrm{H}} \mathrm{His}_{6}$ tag, and this overexpressed YuaB$\mathrm{His}_{6}$ tag contributed the formation of wrinkled biofilm at the liquid-air interface well functions for biofilm formation even with the addition of $\mathrm{His}_{6}$ tag.

\subsection{Verification of surface display of YuaB-His 6 tag}

To identify that YuaB can be used as an anchoring motif for a new B. subtilis cell surface display system, YuaB-His 6 tag was overexpressed in DB104. Vegetative cell of DB104 and DB104(pDE100-Y1) were both reacted with (FITC)labeled anti-rabbit His6 for $1 \mathrm{~h}$ and analyzed by flow cytometry. Flow cytometric histogram of DB104(pDE100Y1) shows increased fluorescence intensity compared that
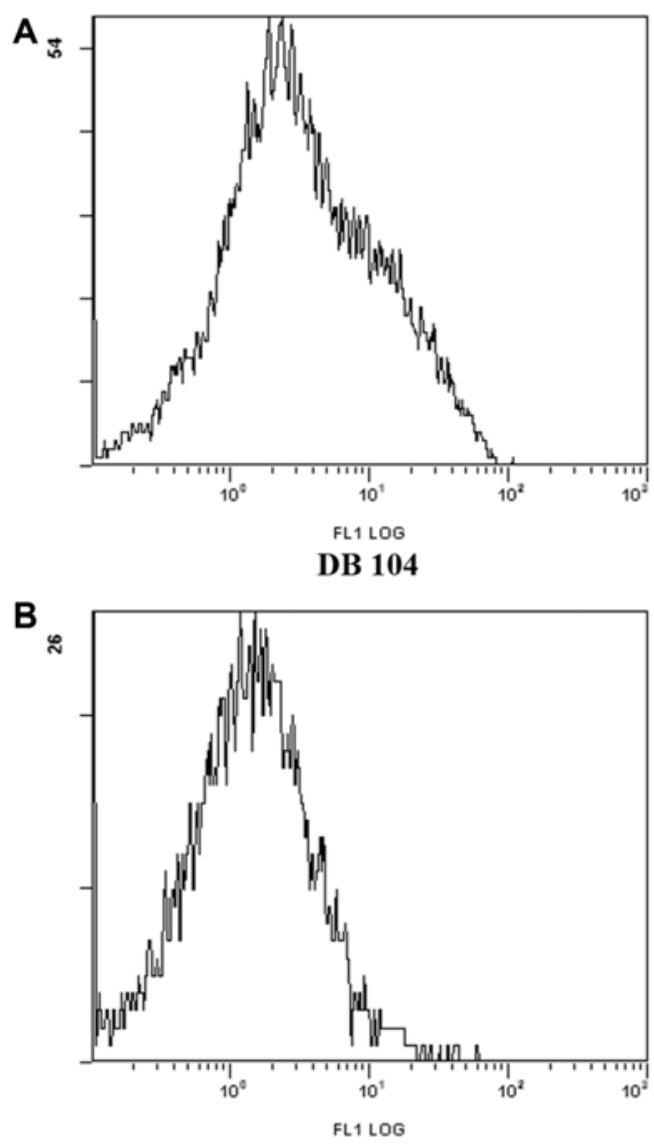

DB 104-proto of control strain DB104 (Fig. 4A). This result demonstrates that YuaB-His ${ }_{6}$ tag was successfully expressed and located on the B. subtilis cell surface. In the preceding study, YuaB was detected in three different cell fractions including the cytoplasm, membrane and non-covalently bounded membrane proteins [34]. Based on this result, we hypothesized that YuaB is located not only in the cell wall but also in the cytoplasmic membrane. To confirm the location of YuaB, protoplast, of which peptidoglycan layer is removed from vegetative cell, was prepared. YuaB-His ${ }_{6}$ tag was observed at protoplast, DB104(pDE100-Y1)-proto (Fig. 4B). This result explains that YuaB of $B$. subtilis located at plasma membrane. Comprehensively, our study illustrates that YuaB, which is a biofilm component, can be used as an anchoring motif for a new $B$. subtilis cell surface display system.

\section{4. $\mathrm{Ni}^{2+}$ and $\mathrm{Cu}^{2+}$ adsorption capacity}

In this study, $\mathrm{His}_{6}$ tag was fused at the C-terminus of YuaB for the flow cytometric analysis of surface display. Poly-

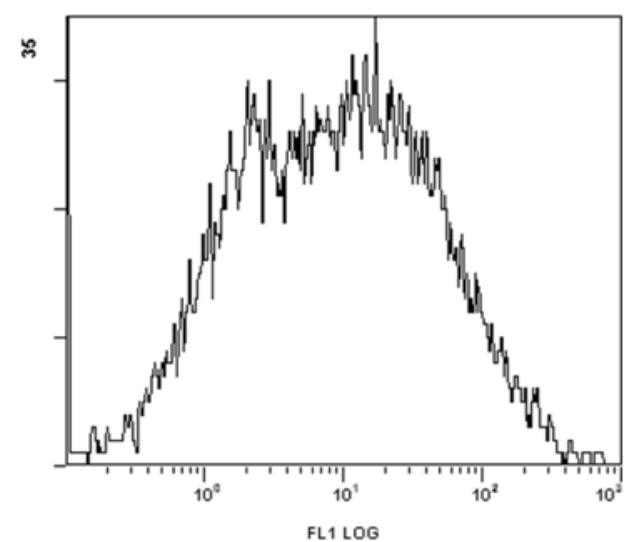

DB 104(pDE100-Y1)

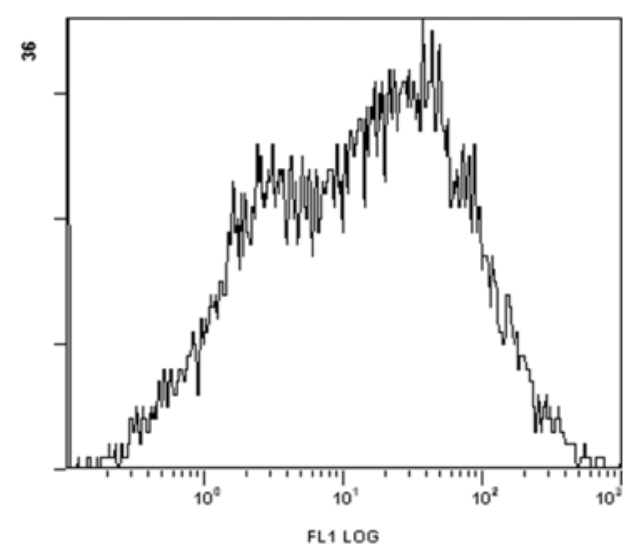

DB 104(pDE100-Y1)-proto

Fig. 4. Flow cytometric analysis of YuaB-His 6 tag overexpressing strain. (A) Flow cytometric histogram of DB104 (left) and DB104(pDE100-Y1) (right). DB104 is used as negative control and surface display of YuaB-His 6 tag was observed by shifted histogram of DB104(pDE100-Y1). (B) Flow cytometric histogram of protoplast analysis. DB104-proto indicates protoplast of Bacillus subtilis DB104. DB104(pDE100-Y1)-proto represents protoplast of DB104(pDE100-Y1). 
A

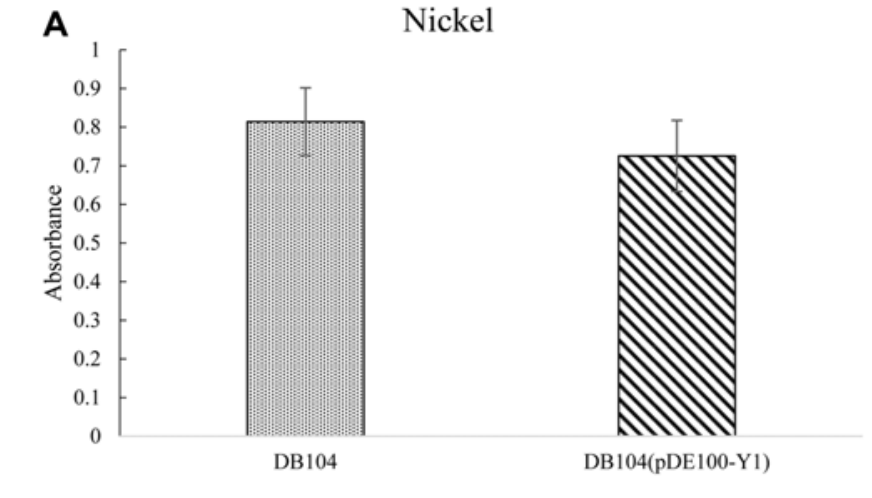

Nickel

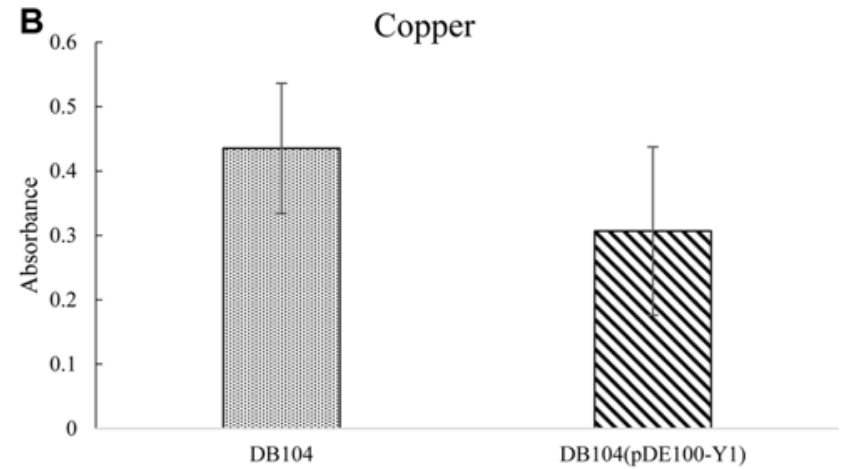

Fig. 5. Atomic adsorption analysis of heavy metal adsorption. (A) $\mathrm{Ni}^{2+}$ adsorption. (B) $\mathrm{Cu}^{2+}$ adsorption. Each graph shows the remaining amount of each metal ion in the solution after treatment with Bacillus subtilis. Respectively, DB104 is negative control. YuaBHis6 is recombinant DB104(pDE100-Y1), which has His6 tag at the C-terminus of YuaB. Standard means a standard control of heavy metal solutions for adsorption analysis.

histidine can adsorb divalent metal ion by forming metalpolyhistidine complex [40,41]. Accordingly, recombinant B. subtilis, DB104(pDE100-Y1), which has $\mathrm{His}_{6}$ tag at Cterminus of YuaB, was utilized for heavy metal adsorption for their functionality. $\mathrm{Cu}^{2+}$ and $\mathrm{Ni}^{2+}$ were selected as the representative heavy metal for $\mathrm{His}_{6}$ tag, which is immobilized on the B. subtilis cell surface using YuaB.

With standard metal solution, DB104, which is used as negative control, also went through same procedure as DB104(pDE100-Y1) to rule out technical variables. Each sample was reacted at $37^{\circ} \mathrm{C}$ for $1 \mathrm{~h}$ to optimize cell condition during the reaction. The graphs show relative remaining amount of each metal ion, $\mathrm{Ni}^{2+}$ and $\mathrm{Cu}^{2+}$, after treatment of standard metal solution with DB104 and DB104(pDE100Y1).

In the case of $\mathrm{Ni}^{2+}$ adsorption, DB104(pDE100-Y1) adsorbed $10 \%$ more $\mathrm{Ni}^{2+}$ of compared to DB104, which is shown as a small decrease in the relative remaining amount of metal (Fig. 5A). In the case of $\mathrm{Cu}^{2+}$, DB104(pDE100Y1) adsorbs $30 \%$ more of $\mathrm{Cu}^{2+} \mathrm{DB} 104$, which is shown as a significant decrease in the relative remaining amount of metal (Fig. 5B). These data mean that YuaB-His ${ }_{6}$ tag has different metal adsorption ability according to the nature of heavy metal ion.

YuaB served successfully for the adsorption of metal ions, $\mathrm{Cu}^{2+}$ and $\mathrm{Ni}^{2+}$, and could be used as motif for a new $B$. subtilis cell surface display system for the other protein with various biotechnological application.

\section{Discussion}

B. subtilis spore display system has been well established and already applied in various biotechnological fields. Contrastively, B. subtilis cell surface display was hardly studied. Herein, we attempted to develop a new B. subtilis cell surface display system using $B$. subtilis biofilm component, YuaB. Recently, biofilm phenomena draw attention to exploit the benefits of biofilm formation [42]. Biofilm is highly structural and characteristic.

YuaB is one of the major proteins, which composes extracellular matrix of $B$. subtilis biofilm. Previously, it has been revealed that YuaB locates in the B. subtilis cell wall [34]. Based on this finding, YuaB has been chosen for an anchoring motif for a new $B$. subtilis cell surface display system in this study. We confirmed that YuaB was successfully overexpressed by $\mathrm{p} 43$ promoter and displayed on the $B$. subtilis cell surface and its surface localization is verified by flow cytometry analysis.

Moreover, from protoplast analysis, YuaB was observed in cytoplasmic membrane of $B$. subtilis. This result provides two possible hypotheses. First, YuaB locates only in the cytoplasmic membrane and penetrate through peptidoglycan layer. Second, YuaB places not only in the plasma membrane but also in the cell wall. The exact position of YuaB needs to be studied in the further studies.

Though we attached $\mathrm{His}_{6}$ tag for the verification of surface display of YuaB, the attached $\mathrm{His}_{6}$ tag can be used for the adsorption and removal of divalent heavy metal for the bioremediation.

Several research groups used engineered microorganisms displaying multiple histidine residues for the adsorption of heavy metal using bacterial surface display technology. We would like to focus and compare those results which were used for the adsorption of $\mathrm{Ni}^{2+}$ among various heavy metal adsorption researches. Several kinds of His tag, with varying length of repeating unit of $\mathrm{His}_{6}$, have been displayed on the surface of $E$. coli cells and B. subtilis spore.

In the case of E. coli, using CS3 pili as an anchoring motif, $276.5 \mathrm{nmol}$ of $\mathrm{Ni}^{2+}$ was removed per mg cell, which is very high value among reported cases [43].

$B$. subtilis spore, having higher thermos-stability and resistance to the low $\mathrm{pH}$ environment, lytic enzymes and 
Table 1. Comparison of bioaccumulation of $\mathrm{Ni}^{2+}$ and $\mathrm{Cu}^{2+}$ with the surface displayed polyhistidine

\begin{tabular}{|c|c|c|c|c|c|c|}
\hline \multirow{2}{*}{$\begin{array}{l}\text { Metal } \\
\text { ion }\end{array}$} & \multirow{2}{*}{ Anchoring motif } & \multirow{2}{*}{$\begin{array}{l}\text { Displayed } \\
\text { peptide }\end{array}$} & \multirow{2}{*}{$\begin{array}{l}\text { Reaction } \\
\text { condition }\end{array}$} & \multicolumn{2}{|c|}{ Bioaccumulation (nmole/mg) } & \multirow{2}{*}{ Reference } \\
\hline & & & & Wild type & Recombinants & \\
\hline \multirow[t]{4}{*}{$\mathrm{Ni}^{2+}$} & YuaB (Bacillus subtilis) & $\mathrm{His}_{6}$ & $37^{\circ} \mathrm{C}$ & 4.68 & $5.32($ cell $)$ & This work \\
\hline & Cot B (B. subtilis) & $\mathrm{His}_{18}$ & $25^{\circ} \mathrm{C}, \mathrm{pH} 7$ & 24.79 & 30.66 (spore) & {$[44]$} \\
\hline & Cot E (B. subtilis) & $\mathrm{His}_{12}$ & $37^{\circ} \mathrm{C}, \mathrm{pH} 7$ & 18.24 & 84.22 (spore) & {$[45]$} \\
\hline & CS3 (Escherichia coli) & $\mathrm{His}_{6}$ & $37^{\circ} \mathrm{C}$ & $80 \pm 2$ & $276.5 \pm 12($ cell $)$ & [43] \\
\hline \multirow[t]{2}{*}{$\mathrm{Cu}^{2+}$} & YuaB (B. subtilis) & $\mathrm{His}_{6}$ & $37^{\circ} \mathrm{C}$ & 11.66 & $15.46($ cell $)$ & This work \\
\hline & GTS1 (Saccharomyces cerevisiae) & $\mathrm{His}_{6}$ & $37^{\circ} \mathrm{C}, \mathrm{pH} 7.8$ & $0.11 \pm 0.03$ & $0.81 \pm 0.02($ cell $)$ & [46] \\
\hline
\end{tabular}

toxic chemicals, was used for similar purpose with $\mathrm{CotB}$ and CotE as anchoring motif. CotB-His ${ }_{18}$ tag displaying spore adsorbed $24 \%$ higher amount of $\mathrm{Ni}^{2+}$ compared to wild spore (30.66 vs. $24.79 \mathrm{nmol} / \mathrm{mg}$ spore) [44]. And, CotE-His $_{12}$ tag displaying spore adsorbed more than $400 \%$ higher amount of $\mathrm{Ni}^{2+}$ compared to wild spore (84.22 vs. $18.24 \mathrm{nmol} / \mathrm{mg}$ spore) [45].

For the adsorption of $\mathrm{Cu}^{2+}$, we can find one reference using GTS1 as an anchoring motif in $S$. cerevisiae surface display system. They report elevated adsorption value $(0.81 \mathrm{nmol} / \mathrm{mg})$ compared to wild type $(0.11 \mathrm{nmol} / \mathrm{mg})$, but the absolute value of adsorption is very low due to different measurement method [46]. All these adsorption data are summarized in Table 1.

In this research, B. subtilis cell which expresses YuaB$\mathrm{His}_{6}$ tag, adsorbed relatively little amount of compared to other surface display system. It can be attributed to the difference experimental condition or measurement system between research groups. Or, it can be from the different length of binding motives such as $\mathrm{His}_{6}, \mathrm{His}_{12}$, and $\mathrm{His}_{18}$.

Using YuaB as a new anchoring motif, B. subtilis cell surface display has several advantages in the industrial aspects. First, it does not need special condition for sporulation. In order to use spore, it takes time for sporulation and spore purification. Moreover, separation process after heavy metal adsorption can be easier than traditional planktonic bacterial surface display system.

Recently, two research papers focusing on B. subtilis cell surface display have been published. Using TasA, another important biofilm formation component, as an anchoring motif, red fluorescent protein mCherry and the antigenic peptides from Echinococcus granulosus parasite, Egtrp and EgA31 have been displayed on the surface of B. subtilis [47]. Another interesting anchoring motif was LysM cell wall binding modules. Cel8A endoglucanase is fused to LysM cell wall binding modules, and this fusion protein was expressed and bound to the surface of $B$. subtilis noncovalently [48].

Our YuaB based surface display system tends to generate biofilm easily, which means bacterial community can be easily separated from water without centrifugation or other labor-intensive procedure.

\section{Acknowledgement}

This work was supported by the Dong-A University research fund.

The authors declare no conflict of interest.

Neither ethical approval nor informed consent was required for this study.

\section{References}

1. Chen, X., C. Gao, L. Guo, G. Hu, Q. Luo, J. Liu, J. Nielsen, J. Chen, and L. Liu (2018) DCEO biotechnology: tools to design, construct, evaluate, and optimize the metabolic pathway for biosynthesis of chemicals. Chem. Rev. 118: 4-72.

2. Clomburg, J. M., A. M. Crumbley, and R. Gonzalez (2017) Industrial biomanufacturing: The future of chemical production. Science. 355: aag0804.

3. Yim, H., R. Haselbeck, W. Niu, C. Pujol-Baxley, A. Burgard, J. Boldt, J. Khandurina, J. D. Trawick, R. E. Osterhout, R. Stephen, J. Estadilla, S. Teisan, H. B. Schreyer, S. Andrae, T. H. Yang, S. Y. Lee, M. J. Burk, and S. Van Dien (2011) Metabolic engineering of Escherichia coli for direct production of 1,4butanediol. Nat. Chem. Biol. 7: 445-452.

4. Kim, S. Y., Y. H. Yang, and K. Y. Choi (2020) Bioconversion of plant hydrolysate biomass into biofuels using an engineered Bacillus subtilis and Escherichia coli mixed-whole cell biotransformation. Biotechnol. Bioprocess Eng. 25: 477-484.

5. Park, S., C. Lee, J. Lee, S. Jung, and K. Y. Choi (2020) Applications of natural and synthetic melanins as biosorbents and adhesive coatings. Biotechnol. Bioprocess Eng. 25: 646-654.

6. Oh, H. D., M. S. Cho, J. S. Kim, M. S. Kim, C. H. Kim, and J. Y. Kang (2020) Identification and characterization of a cocoon degradable enzyme from the isolated strain Bacillus subtilis Bs5C. Biotechnol. Bioprocess Eng. 25: 442-449.

7. Jin, P., L. Zhang, P. Yuan, Z. Kang, G. Du, and J. Chen (2016) Efficient biosynthesis of polysaccharides chondroitin and heparosan by metabolically engineered Bacillus subtilis. Carbohydr. Polym. 140: 424-432.

8. Cho, S. W., J. Yang, S. Park, B. Kim, and S. W. Seo (2019) Complete genome sequence of lactic acid bacterium Pediococcus acidilactici strain ATCC 8042, an autolytic anti-bacterial peptidoglycan hydrolase producer. Biotechnol. Bioprocess Eng. 24: 483-487.

9. Feng, J., Y. Gu, Y. Quan, M. Cao, W. Gao, W. Zhang, S. Wang, C. Yang, and C. Song (2015) Improved poly-gamma-glutamic acid production in Bacillus amyloliquefaciens by modular pathway engineering. Metab. Eng. 32: 106-115.

10. Lee, S. Y. and H. U. Kim (2015) Systems strategies for developing industrial microbial strains. Nat. Biotechnol. 33: 1061-1072. 
11. Gu, Y., X. Xu, Y. Wu, T. Niu, Y. Liu, J. Li, G. Du, and L. Liu (2018) Advances and prospects of Bacillus subtilis cellular factories: From rational design to industrial applications. Metab. Eng. 50: 109-121.

12. Chen, H., J. Ullah, and J. Jia (2017) Progress in Bacillus subtilis spore surface display technology towards environment, vaccine development, and biocatalysis. J. Mol. Microbiol. Biotechnol. 27: 159-167.

13. Kim, J. and W. Schumann (2009) Display of proteins on Bacillus subtilis endospores. Cell Mol. Life Sci. 66: 3127-3136.

14. Freudl, R., S. MacIntyre, M. Degen, and U. Henning (1986) Cell surface exposure of the outer membrane protein OmpA of Escherichia coli K-12. J. Mol. Biol. 188: 491-494.

15. Zhang, Y., W. Dong, Z. Lv, J. Liu, W. Zhang, J. Zhou, F. Xin, J. $\mathrm{Ma}$, and M. Jiang (2018) Surface display of bacterial laccase CotA on Escherichia coli cells and its application in industrial dye decolorization. Mol. Biotechnol. 60: 681-689.

16. Plomp, M., A. M. Carroll, P. Setlow, and A. J. Malkin (2014) Architecture and assembly of the Bacillus subtilis spore coat. PLoS One. 9: e108560.

17. Harrold, Z. R., M. R. Hertel, and D. Gorman-Lewis (2011) Optimizing Bacillus subtilis spore isolation and quantifying spore harvest purity. J. Microbiol. Methods. 87: 325-329.

18. Waller, L. N., N. Fox, K. F. Fox, A. Fox, and R. L. Price (2004) Ruthenium red staining for ultrastructural visualization of a glycoprotein layer surrounding the spore of Bacillus anthracis and Bacillus subtilis. J. Microbiol. Methods. 58: 23-30.

19. Liew, P. X., C. L. C. Wang, and S. L. Wong (2012) Functional characterization and localization of a Bacillus subtilis sortase and its substrate and use of this sortase system to covalently anchor a heterologous protein to the $B$. subtilis cell wall for surface display. J. Bacteriol. 194: 161-175.

20. Nguyen, H. D., T. T. P. Phan, and W. Schumann (2011) Analysis and application of Bacillus subtilis sortases to anchor recombinant proteins on the cell wall. $A M B$ Express. 1: 22.

21. López, D. and R. Kolter (2010) Extracellular signals that define distinct and coexisting cell fates in Bacillus subtilis. FEMS Microbiol. Rev. 34: 134-249.

22. Flemming, H. C. and J. Wingender (2010) The biofilm matrix. Nat. Rev. Microbiol. 8: 623-633.

23. Whitchurch, C. B., T. Tolker-Nielsen, P. C. Ragas, and J. S. Mattick (2002) Extracellular DNA required for bacterial biofilm formation. Science. 295: 1487.

24. Kolodkin-Gal, I., A. K. W. Elsholz, C. Muth, P. R. Girguis, R. Kolter, and R. Losick (2013) Respiration control of multicellularity in Bacillus subtilis by a complex of the cytochrome chain with a membrane-embedded histidine kinase. Genes Dev. 27: 887-899.

25. Cairns, L. S., V. L. Marlow, E. Bissett, A. Ostrowski, and N. R. Stanley-Wall (2013) A mechanical signal transmitted by the flagellum controls signalling in Bacillus subtilis. Mol. Microbiol. 90: 6-21.

26. Chung, J. D., G. Stephanopoulos, K. Ireton, and A. D. Grossman (1994) Gene expression in single cells of Bacillus subtilis: evidence that a threshold mechanism controls the initiation of sporulation. J. Bacteriol. 176: 1977-1984.

27. Dietrich, L. E. P., T. K. Teal, A. Price-Whelan, and D. K. Newman (2008) Redox-active antibiotics control gene expression and community behavior in divergent bacteria. Science. 321: 1203-1206.

28. Wilking, J. N., V. Zaburdaev, M. De Volder, R. Losick, M. P. Brenner, and D. A. Weitz (2013) Liquid transport facilitated by channels in Bacillus subtilis biofilms. Proc. Natl. Acad. Sci. USA. 110: 848-852.

29. Branda, S. S., J. E. González-Pastor, S. Ben-Yehuda, R. Losick, and R. Kolter (2001) Fruiting body formation by Bacillus subtilis. Proc. Natl. Acad. Sci. USA. 98: 11621-11626.
30. Branda, S. S., F. Chu, D. B. Kearns, R. Losick, and R. Kolter (2006) A major protein component of the Bacillus subtilis biofilm matrix. Mol. Microbiol. 59: 1229-1238.

31. Kearns, D. B., F. Chu, S. S. Branda, R. Kolter, and R. Losick (2005) A master regulator for biofilm formation by Bacillus subtilis. Mol. Microbiol. 55: 739-749.

32. Lopez, D., H. Vlamakis, and R. Kolter (2009) Generation of multiple cell types in Bacillus subtilis. FEMS Microbiol. Rev. 33: 152-163.

33. Romero, D., H. Vlamakis, R. Losick, and R. Kolter (2011) An accessory protein required for anchoring and assembly of amyloid fibres in B. subtilis biofilms. Mol. Microbiol. 80: 1155-1168.

34. Ostrowski, A., A. Mehert, A. Prescott, T. B. Kiley, and N. R. Stanley-Wall (2011) YuaB functions synergistically with the exopolysaccharide and TasA amyloid fibers to allow biofilm formation by Bacillus subtilis. J. Bacteriol. 193: 4821-4831.

35. Antelmann, H., H. Tjalsma, B. Voigt, S. Ohlmeier, S. Bron, J. M. van Dijl, and M. Hecker (2001) A proteomic view on genomebased signal peptide predictions. Genome Res. 11: 1484-1502.

36. Wang, P. Z. and R. H. Doi (1984) Overlapping promoters transcribed by Bacillus subtilis sigma 55 and sigma 37 RNA polymerase holoenzymes during growth and stationary phases. $J$. Biol. Chem. 259: 8619-8625.

37. Kawamura, F. and R. H. Doi (1984) Construction of a Bacillus subtilis double mutant deficient in extracellular alkaline and neutral proteases. J. Bacteriol. 160: 442-444.

38. Kim, J. H. and B. G. Kim (2001) Construction of spore mutants of Bacillus subtilis for the development as a host for foreign protein production. Biotechnol. Lett. 23: 999-1004.

39. Merchante, R., H. M. Pooley, and D. Karamata (1995) A periplasm in Bacillus subtilis. J. Bacteriol. 177: 6176-6183.

40. Hochuli, E., W. Bannwarth, H. Döbeli, R. Gentz, and D. Stüber (1988) Genetic approach to facilitate purification of recombinant proteins with a novel metal chelate adsorbent. Nat. Biotechnol. 6: 1321-1325.

41. Asakawa, D. and E. De Pauw (2016) Difference of electron capture and transfer dissociation mass spectrometry on $\mathrm{Ni}^{2+}$-, $\mathrm{Cu}^{2+}$-, and $\mathrm{Zn}^{2+}$-polyhistidine complexes in the absence of remote protons. J. Am. Soc. Mass Spectrom. 27: 1165-1175.

42. Morikawa, M. (2006) Beneficial biofilm formation by industrial bacteria Bacillus subtilis and related species. J. Biosci. Bioeng. 101: 1-8.

43. Saffar, B., B. Yakhchali, and M. Arbabi (2007) Development of a bacterial surface display of hexahistidine peptide using CS3 pili for bioaccumulation of heavy metals. Curr. Microbiol. 55: 273-277.

44. Hinc, K., S. Ghandili, G. Karbalaee, A. Shali, K. A. Noghabi, E. Ricca, and G. Ahmadian (2010) Efficient binding of nickel ions to recombinant Bacillus subtilis spores. Res. Microbiol. 161: 757-764.

45. Kim, W., D. Kim, S. Back, Y. Lee, A. H. Abari, and J. Kim (2019) Removal of $\mathrm{Ni}^{2+}$ and $\mathrm{Cd}^{2+}$ by surface display of polyhistidine on Bacillus subtilis spore using CotE anchor protein. Biotechnol. Bioprocess Eng. 24: 375-381.

46. Kuroda, K., M. Ueda, S. Shibasaki, and A. Tanaka (2002) Cell surface-engineered yeast with ability to bind, and self-aggregate in response to, copper ion. Appl. Microbiol. Biotechnol. 59: 259-264.

47. Vogt, C. M., E. M. Schraner, C. Aguilar, and C. Eichwald (2016) Heterologous expression of antigenic peptides in Bacillus subtilis biofilms. Microb. Cell Fact. 15: 137.

48. Huang, G. L., J. E. Gosschalk, Y. S. Kim, R. R. Ogorzalek Loo, and R. T. Clubb (2018) Stabilizing displayed proteins on vegetative Bacillus subtilis cells. Appl. Microbiol. Biotechnol. 102: 6547-6565.

Publisher's Note Springer Nature remains neutral with regard to jurisdictional claims in published maps and institutional affiliations. 